\title{
PENGARUH PENYULUHAN MENGENAI BAHAYA MEROKOK MENGGUNAKAN MEDIA LEAFLET TERHADAP PERUBAHAN PENGETAHUAN DAN SIKAP SISWA DI SMPN 3 BINTAN TIMUR
}

\section{Influence Counseling About Smoking Using Media Leaflet Against Changes in Student Behavior at SMPN 3 Bintan Timur}

\author{
Indra Martias ${ }^{1}$, Suci Nursamsi ${ }^{2}$
}

${ }^{1}$ Dosen Program Studi DIII Kesehatan Lingkungan Poltekkes Kemenkes Tanjungpinang

${ }^{2}$ Mahasiswa Program Studi DIII Kesehatan Lingkungan Poltekkes Kemenkes Tanjungpinang

\begin{abstract}
Abstrak
Perilaku merokok sudah mulai dilakukan oleh generasi penerus bangsa mulai dari usia sekolah. Untuk itu diperlukan penyuluhan kesehatan mengenai bahaya merokok pada usia sekolah. Tujuan penelitian ini untuk mengetahui pengaruh penyuluhan mengenai bahaya merokok menggunakan media leaflet terhadap perubahan perilaku siswa. Penelitian ini adalah pra eksperimen dengan desain penelitian One Group Pretest-Posttest dengan jumlah sampel sebanyak 104 responden. Analisis data yang digunakan dalam penelitian ini adalah analisis univariant dan bivariant. Hasil penelitian menunjukkan ada hubungan pemberian penyuluhan bahaya merokok menggunakan media leaflet terhadap pengetahuan dan sikap. Hasil pengetahuan $(0,001<0,05)$, sikap $(0,000<0,05)$. Diharapkan adanya dukungan dari pihak sekolah dalam mencegah perilaku merokok siswa dengan mengadakan sanksi tegas terhadap siswa yang terbukti melakukan pelanggaran
\end{abstract}

Kata Kunci : Penyuluhan, Bahaya Merokok, Perubahan Perilaku

\begin{abstract}
Smoking behavior has begun by the next generation of nation starting from school age. For that we need health education about the dangers of smoking at school age. The purpose of this study to determine the effect of education about the dangers of smoking using media leaflets to change student behavior. The type of research used was pre experiment with One Group Pretest-Posttest research design with total sample of 104 respondents. Data analysis used in this research is univariant and bivariant analysis. Normality test results obtained data is not normally distributed, the researchers used the analysiswilcoxon test. The result of wilcoxonanalysis test showed that there was a correlation between giving of smoking hazard to media of leaflet to knowledge, attitude and action of respondent $\mathrm{p}<0,05$. Outcome knowledge $(0.001<0.05)$, attitude $(0,000<0.05)$ and Action $(0.000$ $<0.05)$. It is expected that the support of the school in preventing smoking behavior of students by holding sanctions firmly against students who are proven to violate.
\end{abstract}

Keywords: Counseling, Smoking, Change in Behavior

Korespondensi : Indra Martias

Email : indramartias@ymail.com 


\section{PENDAHULUAN}

WHO memperkirakan separuh kematian di Asia dikarenakan tingginya peningkatan penggunaan tembakau. Angka kematian akibat rokok di negara berkembang meningkat hampir 4 kali lipat. Pada tahun 2000 jumlah kematian akibat rokok sebesar 2,1 juta dan pada tahun 2030 diperkirakan menjadi 6,4 juta jiwa ${ }^{1}$.

Data Riskesdas (2013) menunjukkan perilaku merokok penduduk 15 tahun keatas masih belum terjadi penurunan dari 2007 ke 2013, cenderung meningkat dari 34,2\% tahun 2007 menjadi 36,3\% tahun 2013, begitu pula dengan perokok umur 10-14 tahun ditemukan meningkat $1,4 \%$ dari 6154 anak kemudian proporsi perokok di Indonesia adalah 29,3\%. Proporsi perokok saat ini terbanyak di Kepulauan Riau dengan perokok setiap hari 27,2 persen dan kadang-kadang merokok 3,5\% 2 .

Usia SMP berkisar 12-18 tahun adalah periode penemuan diri dan kepekaan rasa sosial. Pada masa ini kepribadian harus dikembangkan sepenuhnya dan harus sadar akan keharusankeharusan. Kenyataan adanya siswa SMP yang merokok tentu membuat keprihatinan, siswa SMP merupakan anak-anak bangsa yang diharapkan kelak menjadi generasi penerus. Jika sejak dini remaja sudah diracuni oleh rokok, maka hal ini akan berpengaruh tidak hanya pada keadaan fisik tetapi juga mental ${ }^{3}$.

Dipilihnya SMPN 3 Bintan sebagai lokasi penelitian karena berdasarkan survei pendahuluan dari 135 siswa laki-laki di SMP N 3 Bintan Timur, 104 orang siswa laki-laki menyatakan pernah merokok dan hanya 31 siswa tidak merokok. Alasan sebagian siswa pertama kali merokok hanya untuk coba-coba atau ikutikutan teman, namun selanjutnya dapat menjadi kebiasaan yang sulit dihentikan. Hal ini disebabkan karena nikotin yang ada dalam rokok akan menyebabkan efek kecanduan. Pihak sekolah mempunyai peraturan larangan merokok bagi siswa dan berjualan rokok bagi kantin kantin di dalam sekolah, namun siswa masih dapat memperoleh rokok di warung sekitar sekolah.

Berkaitan dengan fenomena di atas, maka peneliti sangat tertarik untuk melakukan penelitian mengenai Pengaruh Penyuluhan Bahaya Merokok Menggunakan Media Leaflet terhadap Perubahan pengetahuan dan sikap siswa SMPN 3 BINTAN. Penyuluhan yang digunakan pada penelitian ini menggunakan media leaflet. Media leaflet dipilih sebagai media karena mudah disimpan, ekonomis, dan bisa berfungsi sebagai remainder bagi sasaran.

\section{METODE}

Penelitian ini merupakan jenis penelitian eksperimen dengan desain penelitian pra eksperimen. Penelitian eksperimen atau percobaan (experimental research) adalah suatu penelitian dengan melakukan kegiatan percobaan (experiment), yang bertujuan untuk mengetahui gejala atau pengaruh yang timbul, sebagai akibat dari adanya perlakuan tertentu atau eksperimen tersebut ${ }^{4}$. Rancangan penelitian ini adalah one group pretest posttest yaitu dengan memberikan pretest terhadap responden sebelum dilakukan penyuluhan, kemudian responden diberikan penyuluhan tentang bahaya merokok menggunakan media leaflet dan setelah diberikan penyuluhan, responden diminta kembali untuk mengisi posttest ${ }^{5}$.

Instrumen yang digunakan pada saat melakukan penelitian ini adalah kuesioner yang berisikan pertanyaan tentang pengetahuan, sikap dan tindakan. Kuesioner diartikan sebagai daftar pertanyaan yang sudah disusun dengan baik, sudah matang, dimana responden tinggal memberi jawaban atau dengan memberikan tanda-tanda tertentu ${ }^{6}$.

\section{HASIL DAN PEMBAHASAN}

Sekolah Menengah Pertama Negeri 3 Bintan Timur sudah Terakreditasi A, saat ini 
Sekolah Menengah Pertama Negeri 3 Bintan Timur. Sekolah ini mempunyai 27 orang guru, 5 orang tata usaha, 2 orang penjaga sekolah, 1 orang petugas kebersihan, 1 orang tukang kebun dan 1 orang supir anak sekolah. 441 siswa yang diantara nya 220 siswa laki-laki dan 221 siswi perempuan, mempunyai 13 ruang kelas, 1 unit ruang kepala sekolah, 1 unit ruang TU, 1 unit ruang laboratorium, 1 unit ruang konseling, 1 unit ruang UKS, 1 unit ruang perpustakaan, 1 ruang mushola, 6 unit kantin sekolah, 1 unit ruang Osis, 9 unit toilet dan 2 unit tempat parkir. Sekolah Menengah Pertama Negeri 3 Bintan Timur memiliki Luas Bangunan 6.500 M2 ${ }^{7}$.

\section{Deskripsi Variabel Penelitian}

Penelitian ini terdiri atas variabel bebas dan variabel terikat. Variabel terikat penelitian ini adalah penyuluhan tentang bahaya merokok dengan menggunakan media leaflet. Penyuluhan tentang bahaya merokok adalah penyampaian materi tentang bahaya merokok menggunakan media leaflet kepada responden. Sedangkan variabel bebas terdiri atas pengetahuan dan sikap siswa SMPN 3 BINTAN.

Pengetahuan siswa tentang bahaya merokok yang dinilai berdasarkan kemampuan dalam menjawab pertanyaan terkait penyuluhan bahaya merokok 8 . Sikap merupakan reaksi atau respon tentang bahaya merokok yang dinilai berdasarkan kemampuan dalam menjawab pertanyaan terkait penyuluhan bahaya merokok 9 .
Tabel 1. Gambaran Variabel Pengetahuan dan Sikap Siswa tentang bahaya merokok dengan menggunakan media leaflet sebelum dan sesudah diberi penyuluhan.

\begin{tabular}{llll} 
& Mean & Sd & Min-Max \\
\cline { 2 - 4 } & 55,77 & 16,089 & $0-89$ \\
\hline $\begin{array}{l}\text { Pengetahuan } \\
\text { Sebelum }\end{array}$ & 62,71 & 17,648 & $0-100$ \\
$\begin{array}{l}\text { Pengetahuan } \\
\text { Sesudah }\end{array}$ & 50,87 & 26,916 & $0-80$ \\
\hline $\begin{array}{l}\text { Sikap } \\
\text { Sebelum }\end{array}$ & 65,19 & 20,994 & $20-100$ \\
\hline $\begin{array}{l}\text { Sikap } \\
\text { Sesudah }\end{array}$ & & \\
\hline
\end{tabular}

Distribusi frekuensi pengetahuan siswa tentang bahaya merokok dengan menggunakan media leaflet, yang menunjukkan bahwa pada hasil sebelum diberi penyuluhan nilai terendah adalah 0 dan nilai tertinggi adalah 89 dengan standar deviasi 16,089 dan nilai rata-rata 55,77. Setelah diberi penyuluhan nilai terendah adalah 0 dan nilai tertinggi adalah 100 dengan standar deviasi 17,648 dan nilai rata-rata 62,71 .

Distribusi frekuensi sikap siswa tentang bahaya merokok dengan menggunakan media leaflet, yang menunjukkan bahwa pada hasil sebelum diberi penyuluhan nilai terendah adalah 0 dan nilai tertinggi adalah 80 dengan standar deviasi 26,916 dan nilai rata-rata 50,87. Setelah diberi penyuluhan nilai terendah adalah 20 dan nilai tertinggi adalah 100 dengan standar deviasi 20,994 dan nilai rata-rata 65,19 .

\section{Pengaruh Variabel Independen terhadap} perubahan pengetahuan, sikap siwa SMPN 3 BINTAN terhadap bahaya merokok

Dalam penelitian ini analisis bivariat dilakukan untuk mengetahui adanya pengaruh pemberian penyuluhan mengenai bahaya merokok dengan menggunakan media leaflet terhadap pengetahuan, sikap dan tindakan siswa

Sekolah Menengah Pertama Negeri 3 Bintan Timur, dengan dilakukannya pengolahan data menggunakan uji wilcoxon Signed Test merupakan alternatif lain dari uji $t$ untuk data 
berpasangan $(\mathrm{t} \text {-paired })^{10}$. Uji non parametris untuk mengukur signifikansi perbedaan antara 2 kelompok data berpasangan berskala interval atau rasio tetapi berdistribusi tidak normal.

Tabel 2. Hasil Uji Normalitas Pengetahuan dan Sikap Responden Sebelum dan Sesudah diberi Penyuluhan mengenai bahaya merokok

\begin{tabular}{|c|c|c|c|c|}
\hline \multirow{3}{*}{ Variabel } & \multicolumn{4}{|c|}{ Shapiro Wilk Test } \\
\hline & \multicolumn{2}{|c|}{ Sebelum Penyuluhan } & \multicolumn{2}{|c|}{ Sesudah Penyuluhan } \\
\hline & Df & pvalue & Df & pvalue \\
\hline Pengetahuan & 104 & 0,000 & 104 & 0,000 \\
\hline Sikap & 104 & 0,000 & 104 & \\
\hline
\end{tabular}

Tabel 2. Menunjukkan bahwa uji normalitas data diatas menggunakan uji Shapiro Wilk Test. Hasil uji normalitas menunjukkan nilai $\mathrm{p}$ value pengetahuan sebelum dan sesudah diberi penyuluhan $0,000(\mathrm{p}<0,05)$, nilai $\mathrm{p}$ value sikap sebelum diberi penyuluhan $0,000(\mathrm{p}<0,05)$ dan nilai $\mathrm{p}$ value setelah diberi penyuluhan 0,001 $(\mathrm{p}<0,05)$, Dapat disimpulkan pengetahuan dan sikap siswa setelah data di uji Normalitas menggunakan uji Shapiro Wilk Test adalah data tidak berdistribusi normal karena hasil $(\mathrm{p}<0,005)$. Adanya pengaruh/perbedaan pengetahuan dan sikap dapat diketahui melalui pengolahan data menggunakan uji Wilcoxon Signed Rank Test yaitu uji turunan dari paired ttest jika data tidak berdistribusi normal. Apabila p<0,05 maka Ha diterima dan Ho ditolak.
Tabel 3. Pengaruh Pemberian Penyuluhan mengenai Bahaya Merokok Menggunakan Media Leaflet terhadap Tingkat Pengetahuan Siswa Sekolah Menengah Pertama Negeri 3 Bintan Timur

\begin{tabular}{|c|c|c|c|c|}
\hline & & $\mathrm{N}$ & $\begin{array}{l}\text { Mean } \\
\text { Rank }\end{array}$ & $\begin{array}{l}P \\
\text { Value }\end{array}$ \\
\hline Pengetahuan & Sebelum & & & 0.001 \\
\hline Penyuluhan & & 104 & 10,00 & \\
\hline Pengetahuan & Setelah & & & \\
\hline Penyuluhan & & 104 & 20,00 & \\
\hline
\end{tabular}

Tabel 3 dapat disimpulkan bahwa hasil uji analisis Wilcoxon pada pengetahuan responden didapatkan nilai signifikan sebesar 0.001. Nilai signifikan lebih kecil dari alfa $(0,001<0,05)$ maka Ho ditolak dan $\mathrm{Ha}$ diterima. Dapat disimpulkan bahwa ada pengaruh signifikan pemberian penyuluhan mengenai bahaya merokok dengan menggunakan media Leaflet terhadap perubahan tingkat pengetahuan siswa Sekolah Menengah Pertama Negeri 3 Bintan Timur.

Tabel 4. Pengaruh Pemberian Penyuluhan mengenai Bahaya Merokok Menggunakan Media Leaflet terhadap Sikap Siswa Sekolah Menengah Pertama Negeri 3 Bintan Timur

\begin{tabular}{llll}
\cline { 2 - 4 } & $\mathrm{N}$ & Mean Rank & P Value \\
\hline Sikap Sebelum diberi Penyuluhan & 104 & 52,35 & 0,000 \\
Sikap Setelah diberi Penyuluhan & 104 & 35,53 & \\
\hline
\end{tabular}

Tabel 4 menunjukkan bahwa hasil uji analisis Wilcoxonpada sikap responden didapatkan nilai signifikan sebesar 0.000.Nilai signifikan lebih kecil dari alfa $(0,000<0,05)$ maka Ho ditolak dan Ha diterima. Dapat disimpulkan bahwa ada pengaruh signifikan pemberian penyuluhan mengenai bahaya merokok dengan menggunakan media Leaflet terhadap perubahan 
sikap siswa Sekolah Menengah Pertama Negeri 3 Bintan Timur.

\section{KESIMPULAN DAN SARAN}

Adapun kesimpulan pada penelitian ini adalah :

a. Distribusi nilai tingkat pengetahuan sebelum diberi penyuluhan nilai terendah adalah 0 dan nilai tertinggi adalah 89 dengan standar deviasi 16,089 dan nilai rata-rata 55,77. Setelah diberi penyuluhan nilai terendah adalah 0 dan nilai tertinggi adalah 100 dengan standar deviasi 17,294 dan nilai rata-rata 62,82.

b. Distribusi nilai sikap sebelum diberi penyuluhan nilai terendah adalah 0 dan nilai tertinggi adalah 80 dengan standar deviasi 26,916 dan nilai rata-rata 50,87. Setelah diberi penyuluhan nilai terendah adalah 20 dan nilai tertinggi adalah 100 dengan standar deviasi 20,994 dan nilai rata-rata 65,19 .

c. Berdasarkan hasil analisis uji wilcoxon menyatakan bahwa hasil tingkat pengetahuan dan sikap responden sebelum dan sesudah diberi penyuluhan didapatkan nilai signifikan ( $\mathrm{p}<0,05)$. Dapat disimpulkan bahwa ada pengaruh signifikan pemberian penyuluhan mengenai bahaya merokok dengan menggunakan media Leaflet terhadap perubahan perilakusiswa Sekolah Menengah Pertama Negeri 3 Bintan Timur.

\section{SARAN}

a. Bagi Siswa Sekolah Menengah Pertama Negeri 3 Bintan Timur

Diharapkan kepada para perokok khususnya para siswa SMPN 3 Bintan Timur agar menghentikan kebiasaan merokoknya. Serta mampu menginplementasikan ilmu pengetahuan yang sudah di dapat dari penyuluhan mengenai bahaya merokok karena hal ini bermanfaat untuk dirinya sendiri mengingat dampak buruk yang diakibatkan dari kebiasaan merokoknya.Selain dapat mengganggu kesehatan, merokok juga dapat mengganggu performanya disekolah.

b. Bagi Sekolah

Sebaiknya sekolah membuat aturan kawasan bebas rokok di lingkungan sekolah.

c. Bagi Dinas Kesehatan

Perlu dilakukan pengenalan dan memperbanyak informasi terkait bahaya merokok sehingga pengetahuan siswa mengenai bahaya merokok tidak berhenti saat diberi penyuluhan saja.

d. Bagi Dinas Pendidikan

Diharapkan kepada pemerintah agar dapat menindaklanjuti perilaku merokok siswa sekolah, dan diharapkan pemerintah dapat memperketat peraturan yang mengatur tentang rokok bagi anak sekolah agar tidak ada lagi yang mengabaikan undang-undang yang berlaku.

\section{DAFTAR PUSTAKA :}

1. Aliansi Pengendalian Tembakau Indonesia (APTI). 2013. Peta Jalan Pengendalian Produk Tembakau Indonesia. Surakarta: Muhammadiyah University Press.

2. Badan Penelitian dan Pengembangan Kesehatan Kementrian Kesehatan RI. 2013. Riset Kesehatan Dasar.

3. Dinas Kesehatan Karanganyar, 2014. Mapping Perilaku Merokok Rumah Tangga di Karanganyar: APDB Tahun 2014.

4. Notoadmodjo, Soekidjo. Metodologi Penelitian Kesehatan. Rineka Cipta : Jakarta, 2014.

5. Notoadmodjo, Soekidjo, Promosi Kesehatan Teor i\& Aplikasi Edisi Revisi 2010. Rineka Cipta : Jakarta,2010

6. Notoatmodjo, Soekidja. Metodologi Penelitian Kesehatan. Jakarta: Rineka Cipta, 2005

7. Sekolah Menengah Pertama Negeri 3 Bintan Timur 2017, Profil SMPN 3 Bintan Timur, Tahun 2017. 
8. Azizah. (2013). Kebahagiaandan Permasalahan di Usia Remaja. Jurnal bimbingan Konseling Islam, Vol 4 No 2.Cropton, J., Horne, N. \& Miller,F. (1992) Clinical Tubrculosis in Muhermann edd. Tuberkulosis klinis, Jakarta : Widya Medika.

9. Kasman,dkk.2017.Studi eksperimen penggunaan media leaflet dan video bahaya merokok pada remaja.

10. Notoatmodjo, Soekidja. Metodologi Penelitian Kesehatan. Jakarta: Rineka Cipta, 2005. 